NASA/TM-2002-211888

ICOMP-2002-05
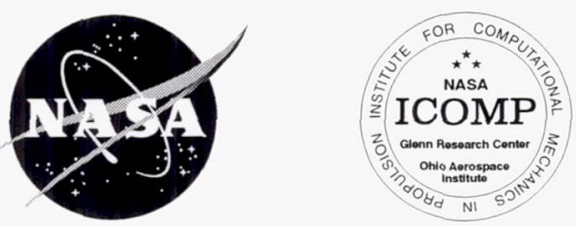

\title{
Multiple-Cycle Simulation of a Pulse Detonation Engine Ejector
}

S. Yungster

Institute for Computational Mechanics in Propulsion, Cleveland, Ohio

H.D. Perkins

Glenn Research Center, Cleveland, Ohio 
Since its founding, NASA has been dedicated to the advancement of aeronautics and space science. The NASA Scientific and Technical Information (STI) Program Office plays a key part in helping NASA maintain this important role.

The NASA STI Program Office is operated by Langley Research Center, the Lead Center for NASA's scientific and technical information. The NASA STI Program Office provides access to the NASA STI Database, the largest collection of aeronautical and space science STI in the world. The Program Office is also NASA's institutional mechanism for disseminating the results of its research and development activities. These results are published by NASA in the NASA STI Report Series, which includes the following report types:

- TECHNICAL PUBLICATION. Reports of completed research or a major significant phase of research that present the results of NASA programs and include extensive data or theoretical analysis. Includes compilations of significant scientific and technical data and information deemed to be of continuing reference value. NASA's counterpart of peerreviewed formal professional papers but has less stringent limitations on manuscript length and extent of graphic presentations.

- TECHNICAL MEMORANDUM. Scientific and technical findings that are preliminary or of specialized interest, e.g., quick release reports, working papers, and bibliographies that contain minimal annotation. Does not contain extensive analysis.

- CONTRACTOR REPORT. Scientific and technical findings by NASA-sponsored contractors and grantees.
- CONFERENCE PUBLICATION. Collected papers from scientific and technical conferences, symposia, seminars, or other meetings sponsored or cosponsored by NASA.

- SPECIAL PUBLICATION. Scientific, technical, or historical information from NASA programs, projects, and missions, often concerned with subjects having substantial public interest.

- TECHNICAL TRANSLATION. Englishlanguage translations of foreign scientific and technical material pertinent to NASA's mission.

Specialized services that complement the STI Program Office's diverse offerings include creating custom thesauri, building customized databases, organizing and publishing research results ... even providing videos.

For more information about the NASA STI Program Office, see the following:

- Access the NASA STI Program Home Page at http://www.sti.nasa.gov

- E-mail your question via the Internet to help@sti.nasa.gov

- Fax your question to the NASA Access Help Desk at 301-621-0134

- Telephone the NASA Access Help Desk at 301-621-0390

- Write to:

NASA Access Help Desk

NASA Center for AeroSpace Information 7121 Standard Drive Hanover, MD 21076 
NASA/TM-2002-211888

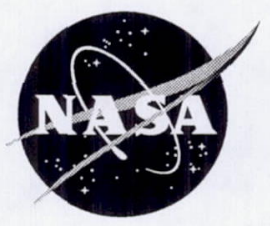

ICOMP-2002-05

AIAA-2002-3630

\section{Multiple-Cycle Simulation of a Pulse Detonation Engine Ejector}

S. Yungster

Institute for Computational Mechanics in Propulsion, Cleveland, Ohio

H.D. Perkins

Glenn Research Center, Cleveland, Ohio

Prepared for the

38th Joint Propulsion Conference and Exhibit

cosponsored by the AIAA, ASME, SAE, and ASEE

Indianapolis, Indiana, July 7-10, 2002

National Aeronautics and

Space Administration

Glenn Research Center 
The Aerospace Propulsion and Power Program at NASA Glenn Research Center sponsored this work.

Available from

NASA Center for Aerospace Information 7121 Standard Drive

Hanover, MD 21076
National Technical Information Service 5285 Port Royal Road Springfield, VA 22100

Available electronically at http:/ /gltrs.grc.nasa.gov 


\title{
MULTIPLE CYCLE SIMULATION OF A PULSE DETONATION ENGINE EJECTOR
}

\author{
S. Yungster \\ Institute for Computational Mechanics in Propulsion \\ Brook Park, Ohio 44142 \\ H.D. Perkins \\ National Aeronautics and Space Administration \\ Glenn Research Center \\ Cleveland, Ohio 44135
}

\begin{abstract}
This paper presents the results of a study involving single and multiple-cycle numerical simulations of various PDE-ejector configurations utilizing hydrogen-oxygen mixtures. The objective was to investigate the thrust, impulse and mass flow rate characteristics of these devices. The results indicate that ejector systems can utilize the energy stored in the strong shock wave exiting the detonation tube to augment the impulse obtained from the detonation tube alone. Impulse augmentation ratios of up to 1.9 were achieved. The axial location of the converging-diverging ejectors relative to the end of the detonation tube were shown to affect the performance of the system.
\end{abstract}

\section{Introduction}

Ejectors are thrust augmentation devices whose performance depends on the efficient energy transfer between the primary and secondary flows. Most of the past research on ejectors has focused on steady primary flows, however, some experimental studies have shown that the introduction of unsteadiness into the primary flow can enhance the energy transfer process and consequently improve the thrust augmentation ${ }^{1}$. The reason for the improvement in performance is that, while a steady ejector relies on viscous shear mixing for the energy transfer, the unsteady ejector achieves part of the energy transfer through more efficient flow entrainment mechanisms that are essentially inviscid. In addition, unsteady ejectors generally require shorter lengths, as compared to steady ejectors, for completing the energy transfer, and therefore have the potential to achieve a more efficient structural design.

It is important to point out that two types of ejector augmentation systems have been considered in the past. They are based on different physical principles to obtain thrust augmentation, and are effective at different flight speeds.

The low-speed ejector systems rely on the low pressures generated by the secondary flow accelerating around the inlet contour ${ }^{2}$. The thrust augmentation is primarily a result of suction forces on the leading edge of the ejector shroud. Such ejector systems, which include those investigated by Lockwood $^{1}$, generate thrust gains at static conditions. However, they rapidly lose their thrust augmentation ability with forward flight. The reason being that, with forward flight, the secondary flow is no longer accelerated around the inlet leading edge. This causes a decrease in the leading edge suction force and a reduction in thrust augmentation. The changes in the secondary flow with flight speed may actually produce thrust losses at cruise conditions ${ }^{2}$.

The second type of thrust augmentation ejector system is the ejector-ramjet, which is most effective from high subsonic to low supersonic speeds ${ }^{3}$. Two classes of ejector-ramjet systems have been proposed; the simultaneous mixing and combustion cycle (SMC), and the closely related independent ramjet stream cycle (IRS) recently proposed by Trefny and Yungster ${ }^{4,5}$.

In the SMC cycle, exhaust from a primary fuel-rich rocket provides some fraction of the fuel required for combustion with the entrained secondary airflow. The rocket and air streams mix and burn simultaneously. This process generally results in thermal choking where mixing is complete, followed by expansion through a nozzle. However, the requirement for complete mixing of the rocket and air streams may result in very long mixing/combustor ducts.

In the IRS cycle complete mixing of the rocket and ramjet streams is not required. In this cycle, the airstream is fueled independently using fuel injectors located upstream in the inlet. The rocket serves as a pilot for the fueled airstream. The IRS cycle has several potential advantages over the SMC cycle which are described in ref. 5.

Numerous methods for introducing unsteadiness into the primary flow have been proposed, including the Spin-Jet, Oscillating-Primary-Jet and Pulse-Jet ejectors ${ }^{1}$. In recent years, the Pulse-Detonation-Engine (PDE) has been recognized as a promising propulsion system that offers advantages in thermodynamic cycle efficiency and hardware 
simplicity ${ }^{6,7}$. Since PDEs are highly unsteady devices there is considerable interest in investigating their performance in an ejector configuration.

The objective of this paper is to present an initial study of the performance of several PDE ejector configurations at static conditions, and for single and multiple cycles.

\section{Numerical Method}

The analysis was carried out using an in-house developed time-accurate CFD code ${ }^{8}$. The code solves the axisymmetric Navier-Stokes equations for a nonequilibrium mixture of thermally perfect gases, using an implicit, total variation diminishing (TVD) algorithm.

Since the main flow entrainment mechanisms in unsteady ejectors are essentially inviscid, we neglect the viscous terms, and therefore, use the Euler equations with finite rate chemistry. In our formulation, the global continuity equation is replaced by $n_{s}$ species conservation equations, where $n_{s}$ denotes the number of species.

The numerical method used for solving the governing equations is described in detail in Ref. 8, and briefly summarized here. The equation set is solved using a fully implicit, first-order-accurate in time, variable-step backward differentiation formula (BDF) method. The numerical fluxes are evaluated using a second-order spatially accurate TVD scheme. The resulting equations are then linearized in a conservative manner and solved iteratively, by using a lower-upper relaxation procedure consisting of successive Gauss-Seidel (LU-SGS) sweeps.

The chemical reaction mechanism for hydrogen-oxygen combustion was based on Jachimowski's model (Ref. 9,10), and consists of 19 elementary reactions among 9 species. Reactions involving $\mathrm{N}_{2}$ were neglected.

In order to maintain adequate numerical resolution of the detonation wave front without the need to use thousands of grid points, a multi-level, dynamically adaptive grid is utilized. Figure 1 shows a section of the grid at three different times as the detonation wave moves from left to right. The grid constantly adapts to keep the detonation front within the finest grid level. An arbitrary number of levels can be specified. Nine grid levels were used in the present study, and 100 points were included in the finest grid level.

\section{Results}

Finite rate chemistry calculations were used to compute the flow in various PDE ejector configurations. In this paper, only development of detonations with direct initiation were considered. A high pressure, high temperature driver gas, consisting of $\mathrm{H}_{2}-\mathrm{O}_{2}$ equilibrium combustion products, was used in a small region next to the closed end (head-end) of the detonation tube, as described in Ref. 10. A driver pressure ratio of 50 was used in the present study.

To verify that this computational approach yields Chapman-Jouguet detonations, the detonation velocity was plotted as a function of time for a stoichiometric $\mathrm{H}_{2}-\mathrm{O}_{2}$ mixture, at $p_{0}=0.4 \mathrm{~atm}$. and $T_{0}=298 \mathrm{~K}$, and compared the results with predictions from the CEA equilibrium code of Gordon and $\mathrm{McBride}^{11}$. It is observed in figure $2 \mathrm{a}$ that after an initial overshoot during the short transient phase, the detonation speed reaches a nearly constant value which is in very good agreement with that predicted by the CEA code. Figure $2 \mathrm{~b}$ plots nondimensional pressure and temperature profiles immediately behind the detonation front, showing that the von Neumann spike conditions are computed accurately.

A schematic of the PDE-Ejector configuration considered in this study is shown in fig. 3 . The boundary conditions at the ejector inflow plane depend on the direction of the flow. If the flow was into the ejector, total pressure and temperature, $p_{t o t}$ and $T_{t o t}$ were specified (subsonic inflow boundary). If the flow was out of the ejector, the static pressure was specified and the remaining variables were extrapolated from the interior (subsonic outflow boundary). At the ejector exit plane, the subsonic outflow boundary condition was specified. All calculations considered a stoichiometric $\mathrm{H}_{2}-\mathrm{O}_{2}$ mixture at $p_{0}=1.0 \mathrm{~atm}$. and $T_{0}=298 \mathrm{~K}$, and $p_{\text {tot }} / p_{0}=1.05$. The ambient pressure was set to $1.0 \mathrm{~atm}$. All the calculations were carried out for a detonation tube diameter, $d_{t}$, of 2.6 in. and for ejector dimensions $L_{1}=13$ in., and $L_{2}=26$ in.

The first calculation considered a detonation tube having a length, $L_{t}$, of 72 in. The ejector cone angles were $\theta_{1}=$ $10^{\circ}$ and $\theta_{2}=3.5^{\circ}$. The location of the ejector throat, $\mathrm{L}_{\mathrm{th}}$, was set at $\mathrm{L}_{\mathrm{th}}=2.6 \mathrm{in}$. downstream of the detonation tube end. The ejector throat diameter was set at $\mathrm{D}_{\text {th }}=8.22 \mathrm{in}$., corresponding to an ejector area ratio, $R_{\text {Ath }}=10$, where $R_{\text {Ath }}$ is defined as

$$
R_{\text {Ath }}=\frac{\text { ejector area at throat }}{\text { detonation tube area }}
$$

Figure 4 shows the contribution to the thrust force and impulse from the detonation tube, ejector shroud and the small base area at the end of the detonation tube, for a single PDE cycle. The total force and impulse on the PDE-ejector system is also shown. The contribution of the base area was always negligible in all cases considered. All forces were computed by integrating the instantaneous pressure over the surface area.

The force on the detonation tube (fig. 4a) shows an initial large value that arises from the ignition mechanism used in 
the numerical simulations. No attempt to correct for this artificial force was made in the present study, since the focus is to investigate the relative thrust augmentation obtained in the various configurations studied. This initial short duration spike is followed by a longer plateau region of $2.5 \mathrm{~ms}$ duration and a subsequent decay to zero. It is primarily during this level pressure duration that PDE thrust is generated. The ejector force plot shows a sharp negative spike near $0.7 \mathrm{~ms}$ that is caused by the strong shock impinging on the converging section of the ejector. Figure $5 b$ shows that the total impulse is smaller than that obtained by the PDE tube alone. That is, the ejector is exerting a drag force that reduces the performance of the system.

The poor performance in this case is the result of the strong shock exiting the detonation tube reflecting from the converging section of the ejector shroud. Therefore, an obvious improvement could be achieved by sliding the ejector upstream. Also, one could take more advantage of this strong shock by increasing the diverging angle $\theta_{2}$. The second case therefore considers the same ejector, but moved upstream relative to the tube, such that the ejector throat is 1.4 in. upstream of the end of the detonation tube (that is $L_{t h}=-1.4$ ) In addition, the divergence angle was increased to $\theta_{2}=10^{\circ}$.

Figure 5 shows the force and impulse results for the second case. These changes had no effect on the detonation tube force and impulse, however, there was a substantial effect on the forces acting on the ejector shroud. At $0.7 \mathrm{~ms}$, there is now a sharp positive spike in the ejector force. The positive force continues until around $2.2 \mathrm{~ms}$ followed by alternating, smaller negative and positive forces. Figure $5 \mathrm{~b}$ shows that in this case there is a significant increase in the total impulse of the system, (29.96 N-s compared to 15.70 for the PDE tube alone), corresponding to an impulse augmentation, $\psi$, of $\psi=1.9$.

Additional cases were computed to examine the effect of ejector area ratio, $\mathrm{R}_{\mathrm{Ath}}$, on the performance of the PDE-ejector. The results are shown in fig. 6 . The delay in the arrival of the shock front at the ejector shroud for increasing area ratio can be seen in the first peak in total force between 0.7 and $1.0 \mathrm{~ms}$ approximately. This results in an steeper rise in total impulse initially for the $R_{\text {Ath }}=10$ case. After nearly 8 $\mathrm{ms}$, however, there are small differences in the total impulse generated. There is no general trend in performance over this range of area ratios.

The mass flow rate for area ratios of 20 and 30 is shown in fig. 7. This figure shows that the secondary flow is alternating between positive and negative mass flow rates for both cases. On average (over the nearly $8 \mathrm{~ms}$ of operation) there is a net positive secondary flow of $1.55 \mathrm{~kg} / \mathrm{s}$ for fig. 7a, and $1.17 \mathrm{~kg} / \mathrm{s}$ for fig. $7 \mathrm{~b}$. The average primary mass flow rate for both cases is $1.36 \mathrm{~kg} / \mathrm{s}$.
The next case considers the same detonation tube, but instead of an ejector shroud, a diverging nozzle, having the same length $\left(L_{2}=26\right.$ in. $)$ and divergence angle $\left(\theta_{2}=10^{\circ}\right)$ as the previous ejector, is attached at the end of the detonation tube. There is no secondary flow in this case, and only the constant area tube is fueled. Since the "throat" area is identical to the detonation tube area, this case will be denoted as having an area ratio $\mathrm{R}_{\text {Ath }}=1.0$.

Figure 8 shows the force and impulse for this configuration. The force on the detonation tube remains unchanged from the previous cases. The force on the nozzle is also plotted. This force is initially zero until the shock wave reaches the end of the detonation tube. At that time, a sharp rise is observed. The force on the nozzle peaks at around $1.2 \mathrm{~ms}$ and subsequently decreases and remains negative from around $1.8 \mathrm{~ms}$ until the end of the calculation. Note that the force on the nozzle is a smooth function of time as opposed to the force on the ejector in the previous cases which show periodic oscillations resulting from shock reflections in the ejector.

Figure $8 \mathrm{~b}$ shows that in this case, there is also an increase in the total impulse over that obtained for the PDE tube alone. The impulse augmentation, however is $\psi=1.4$, significantly smaller than that achieved with the ejector systems. The lower performance for this case is a result of the below ambient pressures acting on the nozzle once the shock front leaves the nozzle. A comparison of the total impulse obtained in the present case and in two of the previous ejectors is shown in fig. 9.

Note that other nozzle geometric configurations could have been considered for comparison with the ejector (for example, a nozzle having a different divergence angle but the same exit area as the ejector). Such additional configurations are currently being investigated.

Experimental studies of the effects of nozzles on the performance of PDEs have been carried out by Daniau et al. ${ }^{12}$. They reported impulse augmentation values ranging from 1.2 to 1.8 for different diverging nozzles.

The results presented so far have considered a single PDE cycle. However, PDE-ejector systems normally require several detonation cycles before they reach a "limit cycle" operation. The final case presented in this paper attempts to address this issue by carrying out a multi-cycle computation of a PDE-ejector system.

In order to reduce the computational time, a shorter tube $\left(\mathrm{L}_{\mathrm{t}}=39.4 \mathrm{in}\right.$.) was considered, and the ejector convergence angle was reduced to $\theta_{1}=5^{\circ}$. An ejector with an area ratio of 10 was considered. 
Results of this calculation are presented in fig. 10, which shows the temporal evolution of the PDE ejector flowfield during almost three complete cycles. The detonation is initiated at $\mathrm{t}=0.0 \mathrm{~ms}$, and propagates downstream until it reaches the end of the detonation tube at approximately $0.35 \mathrm{~ms}$. Subsequently, a strong shock followed by the combustion products expand into the ejector. At $4.52 \mathrm{~ms}$ a fresh combustible mixture is introduced into the tube (a pure oxygen buffer zone is used to separate the hot combustion products from the fresh combustible mixture). At $7.63 \mathrm{~ms}$ the detonation tube is completely filled with the new combustible mixture, and at $8.21 \mathrm{~ms}$ the second detonation cycle is started. Subsequent times $(\mathrm{t}=8.42 \mathrm{~ms}$ to $\mathrm{t}=15.31 \mathrm{~ms})$ show the same sequence of events described for the first cycle. At $\mathrm{t}=16.37 \mathrm{~ms}$, the third detonation cycle has been started, and the remaining figures show the subsequent propagation of the detonation wave.

The thrust forces over the 5 cycles are shown in fig. 11, and the impulse and mass flow rates are shown in fig. 12 . While the oscillatory pattern is similar from cycle to cycle, some differences are clearly observed, such as the peak values in the ejector shroud force. More cycles may be required to establish some kind of limit cycle. The impulse plot shows that, after the first cycle, the ejector augmentation is smaller. After five cycles the impulse augmentation was $\psi=1.7$. The mass flow rate plot shows the same alternating between inflow and outflow for the secondary stream. The average secondary mass flow rate varies from cycle to cycle but is always positive, as shown in table 1 . Note that the mass flow rates in the first cycle are substantially different from the others. This is due to the fact that the first cycle does not include the filling process. The first cycle started with the tube already filled with the detonable mixture.

\section{Conclusions}

There is a significant amount of energy stored in the strong shock wave exiting the detonation tube. If no ejector or nozzle is added at the end of the tube, this energy will be simply dissipated into the surrounding air. By adding an ejector (or a nozzle) some of this energy can be utilized for the production of thrust.

The present computations indicate that a PDE-ejector configuration produces higher impulse than a PDE-tube-nozzle combination having the same length and divergence angle. The higher performance of the PDE-ejector is partly due to its capacity to entrain secondary air, which prevents the sub-ambient pressures that develop in the PDE-tube-nozzle system once the shock wave exits the nozzle. Impulse augmentations of 1.9 and 1.4 were obtained for the PDE-ejector and PDE-tube-nozzle configurations respectively.

The axial location of the ejector shroud relative to the end of the detonation tube is an important parameter. The ejector shroud should be placed in a location such that the shock wave exiting the detonation tube impinges on the diverging section of the ejector shroud. The ejector area ratio had a small effect on the performance of the PDE over the range investigated in this study $\left(10<\mathrm{R}_{\mathrm{Ath}}<30\right)$.

The multi-cycle PDE-ejector calculation showed that after 5 cycles, an impulse augmentation factor of 1.7 was achieved. The average secondary mass flow rate remained positive for each cycle.

\section{References}

1. Porter, J.L. and Squyers, R.A., "A Summary/Overview of Ejector Augmentor Theory and Performance," ATC Report No. R-91100/9CR-47A, Sept. 1979.

2. Presz, W., Reynolds, G. and Hunter, C., "Thrust Augmentation with Mixer/Ejector Systems," AIAA paper 2002-0230, January 2002.

3. Heiser, W.H. and Pratt, D.T., Hypersonic Airbreathing Propulsion, pp. 446-472, American Institute of Aeronautics and Astronautics, Washington, D.C, 1994.

4. Trefny, C.J., "An Air-Breathing Launch Vehicle Concept for Single-Stage-to-Orbit," AIAA Paper 99-2730, 1999

5. Yungster, S. and Trefny, C.J., "Analysis of a New Rocket-Based Combined-Cycle Engine Concept at Low Speed," AIAA paper 99-2393, June 1999.

6. Heiser, W.H. and Pratt, D.T., "Thermodynamic Cycle Analysis of Pulse Detonation Engines", Jrn. of Propulsion and Power, Vol. 18, No. 1, January-February 2002.

7. Kailasanath, K., "Recent Developments in the Research on Pulse Detonation Engines," AIAA paper 2002-0470, January 2002.

8. Yungster, S. and Radhakrishnan, K., "A Fully Implicit Time Accurate Method for Hypersonic Combustion: Application to Shock-Induced Combustion Instability," Shock Waves, Vol. 5, 1996, pp. 293-303.

9. Jachimowski, C.J., "An Analytical Study of the Hydrogen-Air Reaction Mechanism with Application to Scramjet Combustion,” NASA TP-2791, Feb. 1988.

10. Yungster, S. and Radhakrishnan, K., "Computational Study of Near-Limit Propagation of Detonation in Hydrogen-Air Mixtures," AIAA paper 2002-3712, July 2002.

11. McBride, B.J. and Gordon, S., "Computer Program for Calculation of Complex Chemical Equilibrium Compositions and Applications. II. Users Manual and Program 
12. Daniau, E., Zitoun, R., Couquet, C. and Desbordes, D., "Effects of Nozzles of Different Length and Shape on the Propulsion Performance of Pulsed Detonation Engines," in High-Speed Deflagration and Detonation, Eds. G.D. Roy, S.M. Frolov, D. Netzer and A. Borisov. Moscow, 2001: ELEX-KM Publ. pp 251-262.

Table 1: Average mass flow rates $(\mathrm{kg} / \mathrm{s})$

\begin{tabular}{|c|c|c|}
\hline Cycle & $\begin{array}{c}\text { Secondary mass flow } \\
\text { rate }\end{array}$ & $\begin{array}{c}\text { Primary mass flow } \\
\text { rate }\end{array}$ \\
\hline \hline $1^{\mathrm{a}}$ & 0.82 & 0.76 \\
\hline 2 & 2.44 & 1.20 \\
\hline 3 & 4.28 & 1.27 \\
\hline 4 & 2.18 & 1.21 \\
\hline 5 & 2.94 & 1.16 \\
\hline
\end{tabular}

${ }^{\mathrm{a} D i f f e r e n t}$ starting condition

$t_{1}$

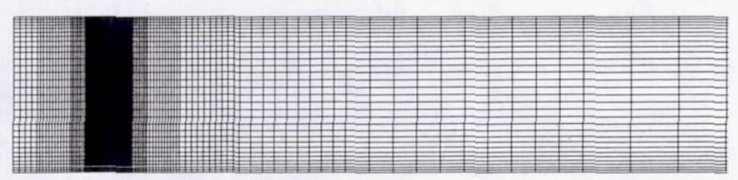

$t_{2}$

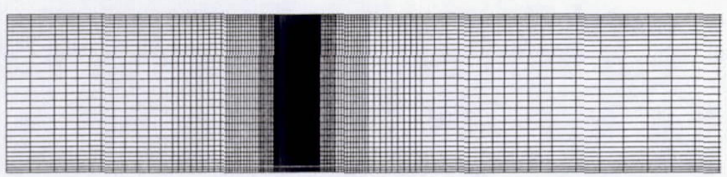

$t_{3}$

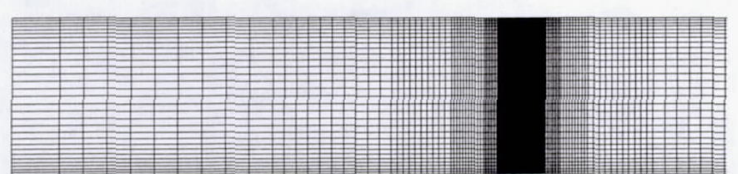

Fig. 1. Computational grid at three different times.
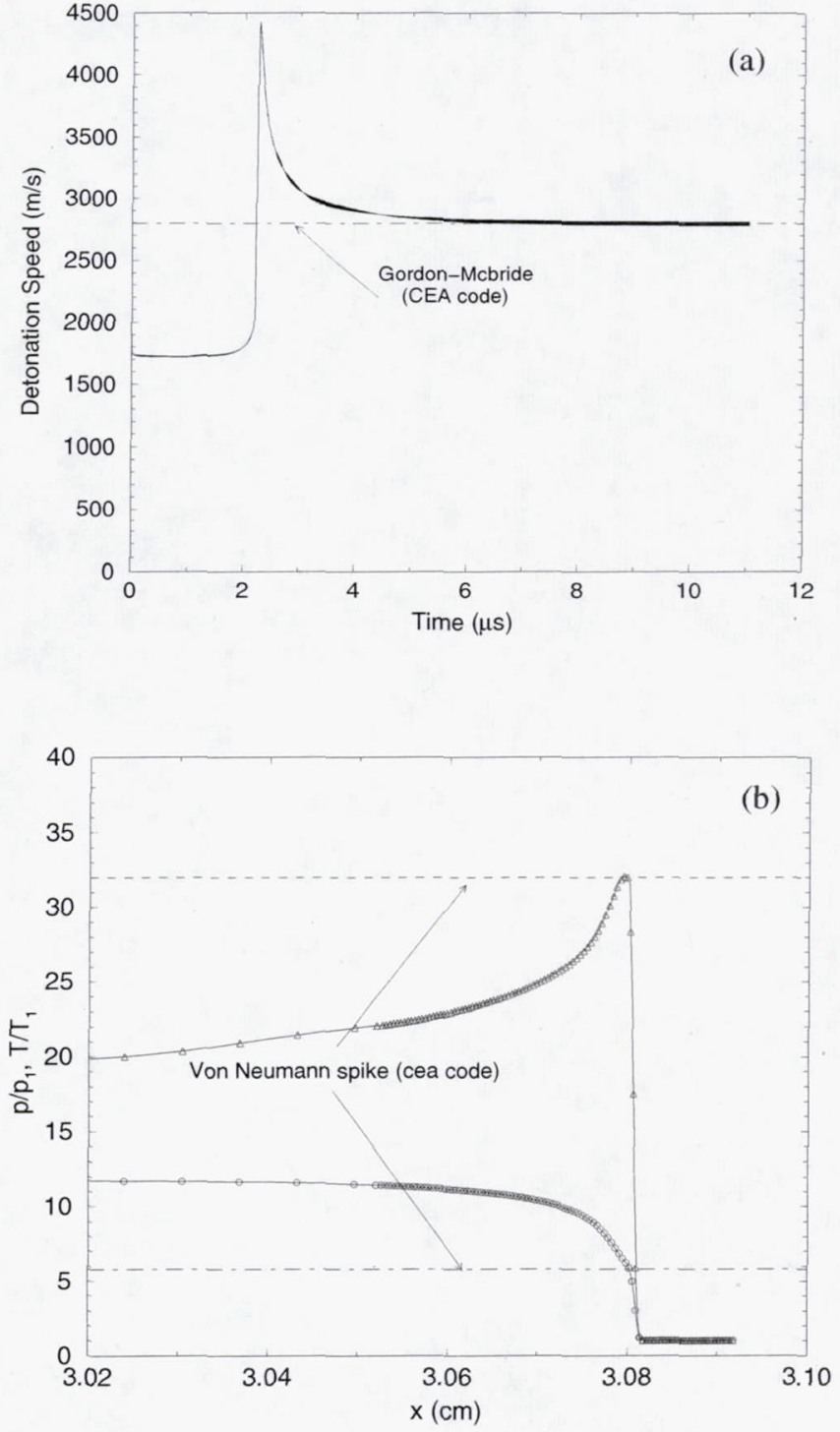

Fig. 2. (a) Detonation speed as a function of time and (b) nondimensional pressure and temperature behind detonation front. $\mathrm{H}_{2}-\mathrm{O}_{2} ; p_{0}=0.4 \mathrm{~atm}, T_{0}=298.0 \mathrm{~K}, \phi=1.0$ 

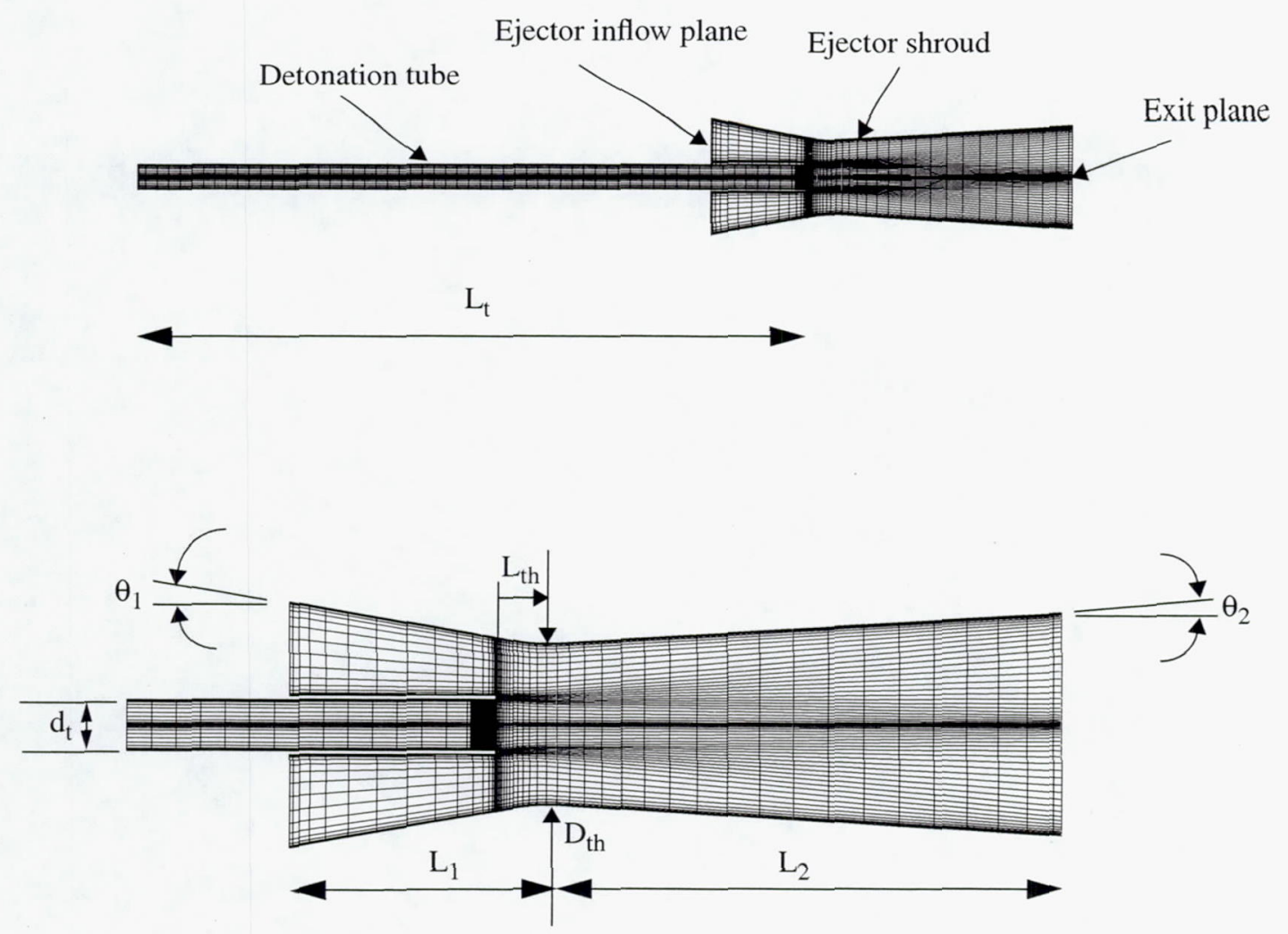

Fig. 3. Schematic of PDE-Ejector configuration. (Only every third grid point is shown)
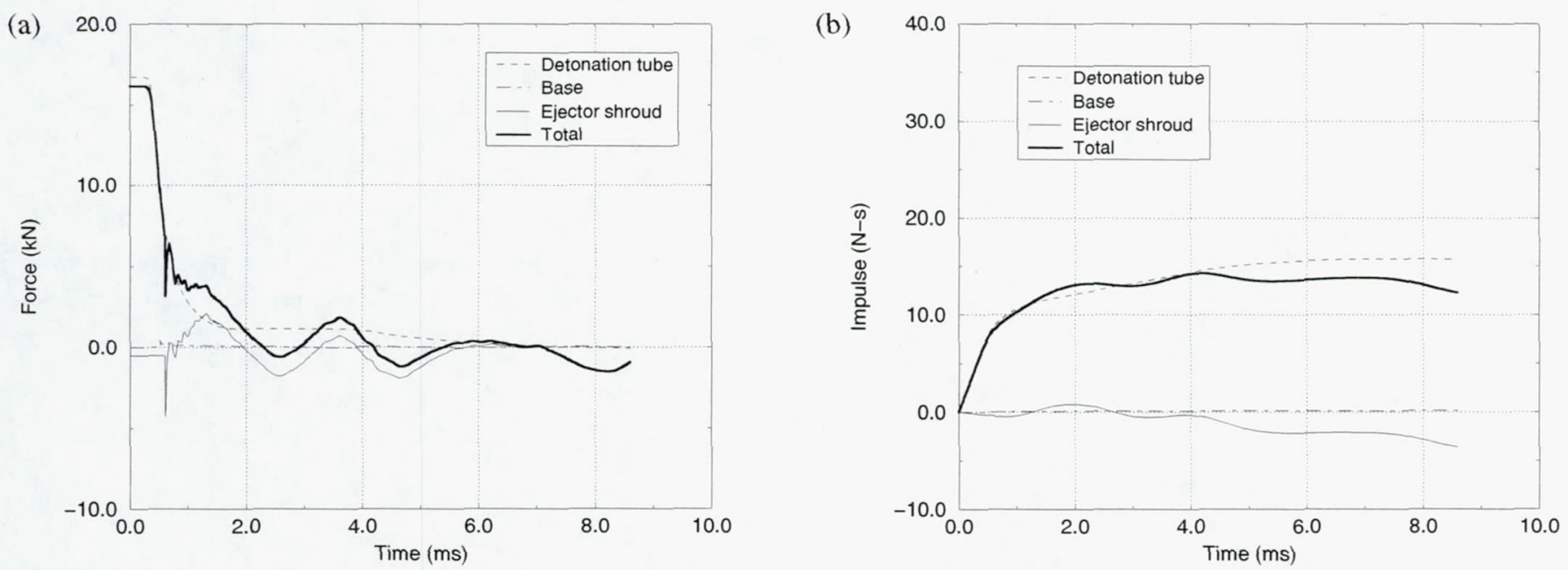

Fig. 4. Force (a) and impulse (b) as a function of time for a PDE-ejector. $\mathrm{L}_{\text {th }}=2 \cdot 6^{\prime \prime}, \theta_{2}=3 \cdot 5^{\circ}, \mathrm{R}_{\text {Ath }}=10$ 

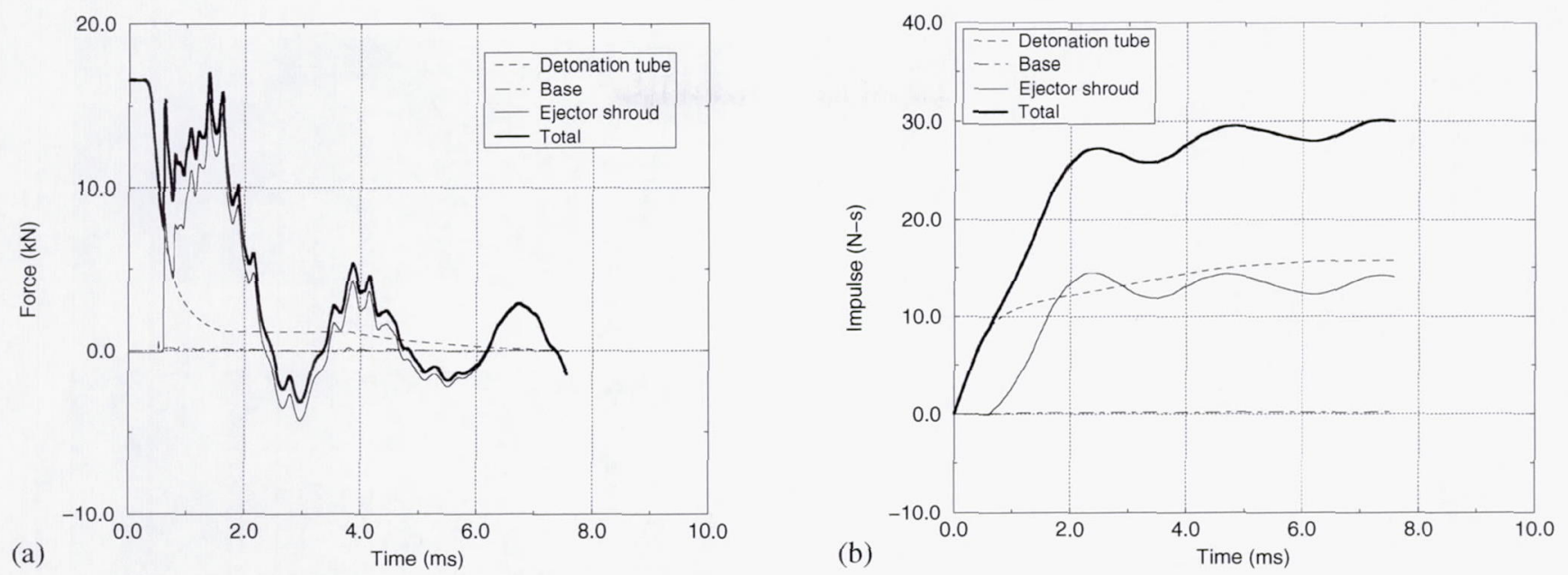

Fig. 5. Force (a) and impulse (b) as a function of time for a PDE-ejector. $L_{\text {th }}=-1.4^{\prime \prime}, \theta_{2}=10^{\circ}, R_{\text {Ath }}=10$
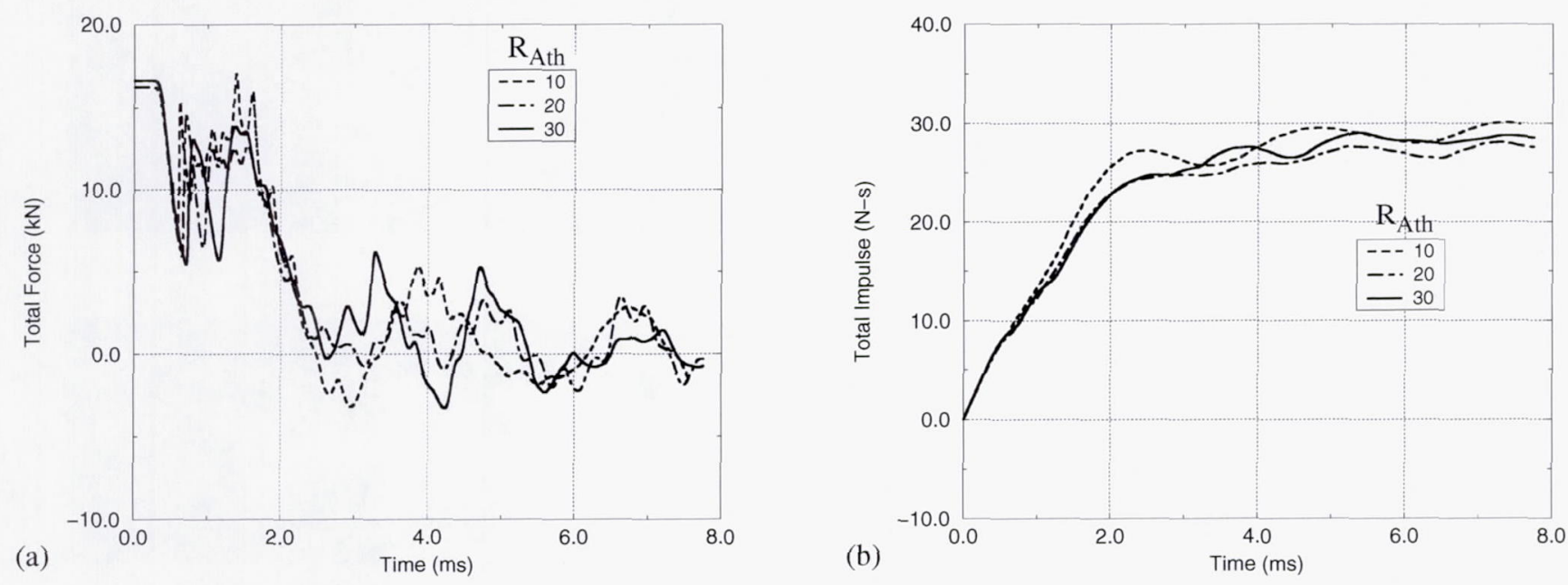

Fig. 6. Total force (a) and impulse (b) as a function of time for three PDE-ejectors. $L_{\text {th }}=-1.4 ", \theta_{2}=10^{\circ}$
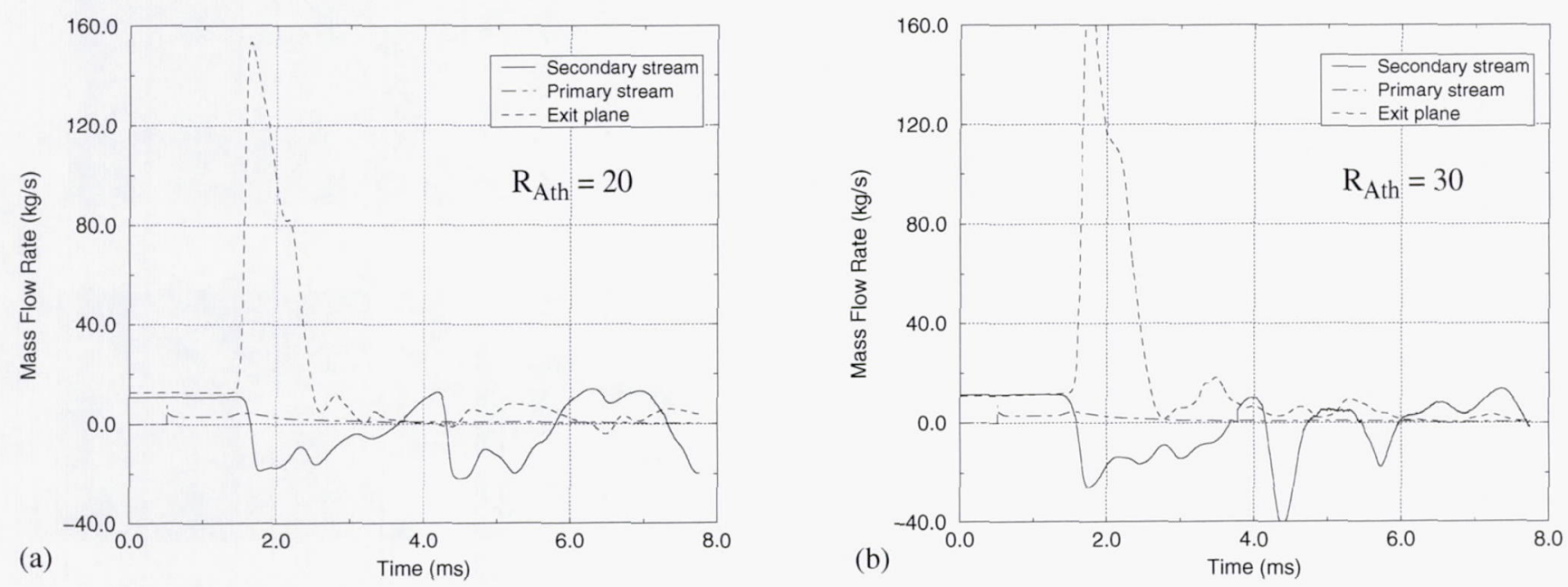

Fig. 7. Mass flow rate as a function of time for two PDE-ejectors. $L_{\text {th }}=-1.4^{\prime \prime}, \theta_{2}=10^{\circ}$ 

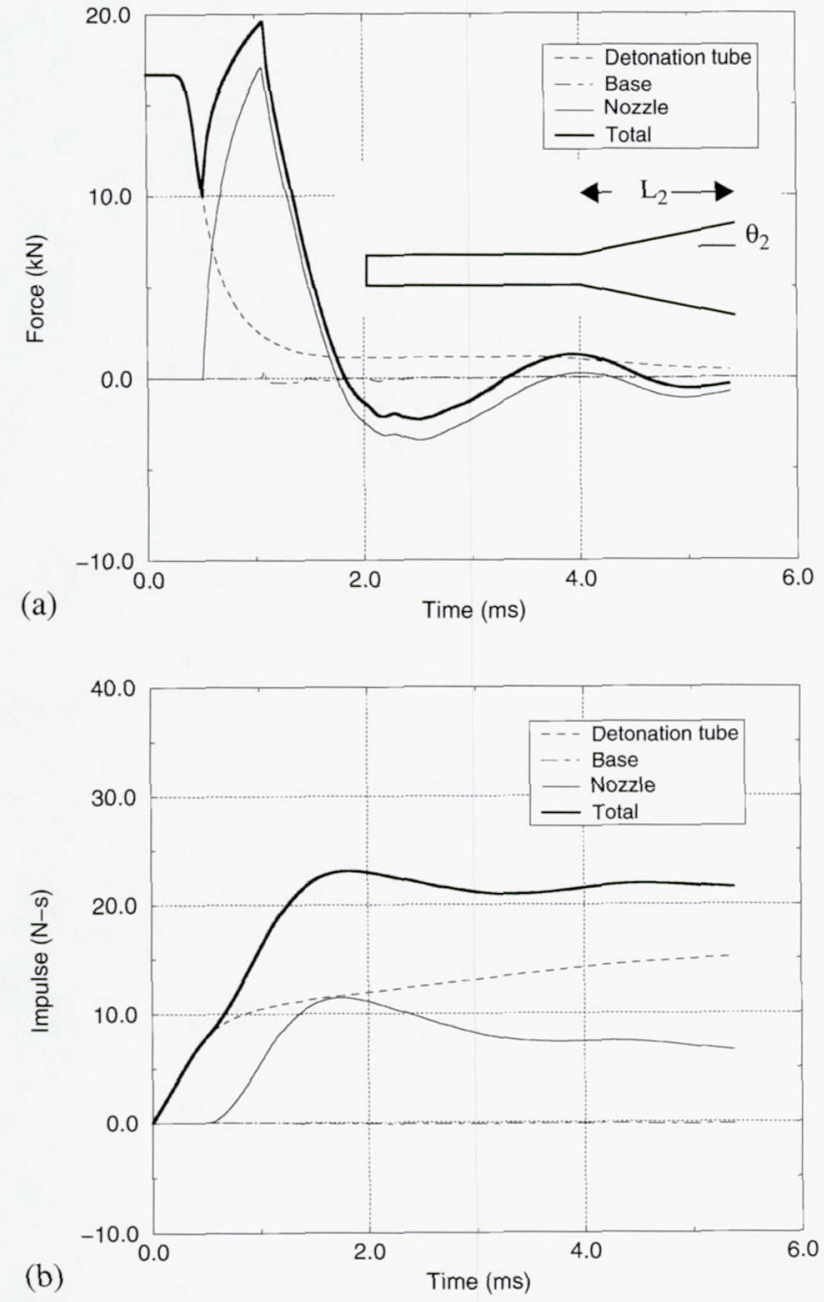

Fig. 8. Force (a) and impulse (b) as a function of time for a PDE with a diverging nozzle $\left(\mathrm{R}_{\mathrm{Ath}}=1, \mathrm{~L}_{2}=26^{\prime \prime}, \theta_{2}=10^{\circ}\right)$.

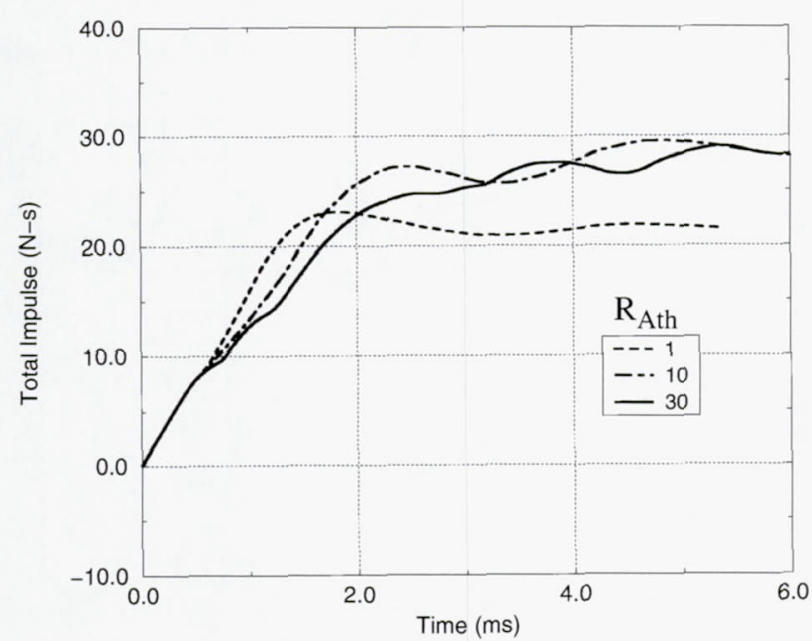

Fig. 9. Total impulse as a function of time for three PDE configurations.
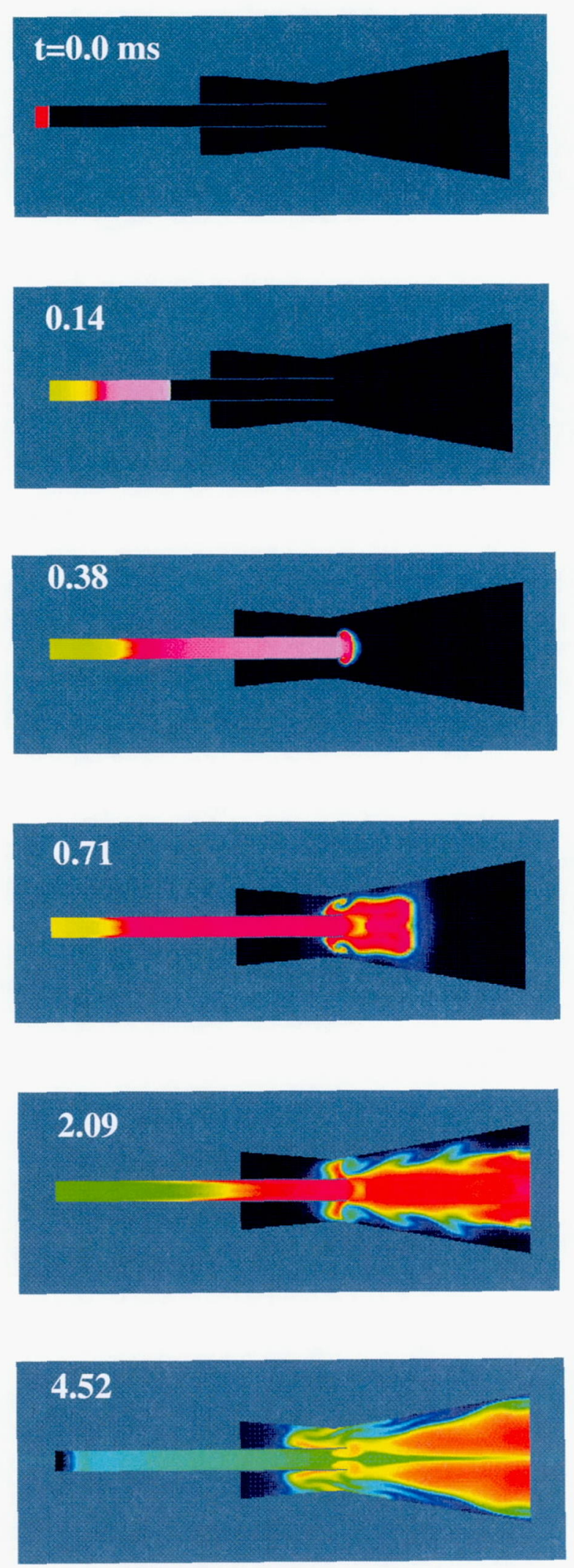

Fig. 10. Multi-cycle simulation showing nondimensional temperature contours for an $\mathrm{H}_{2}-\mathrm{O}_{2}$ PDE-Ejector; $\mathrm{P}_{0}=1.0$ atm.; $\mathrm{T}_{0}=298 \mathrm{~K} ; \phi=1.0 ; \mathrm{p}_{\text {tot }}=1.05 \mathrm{~atm}$. 

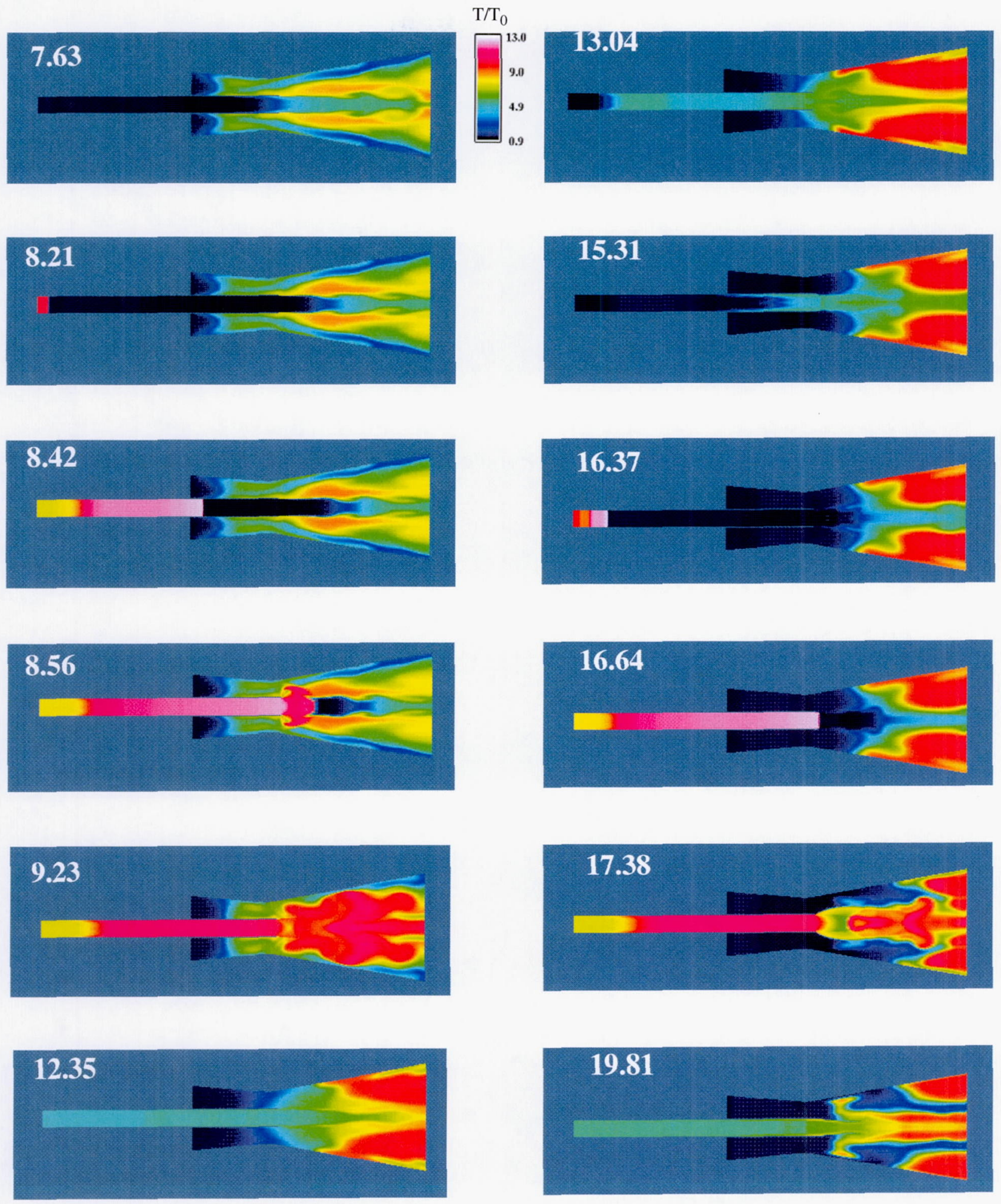

Fig. 10. Concluded. 

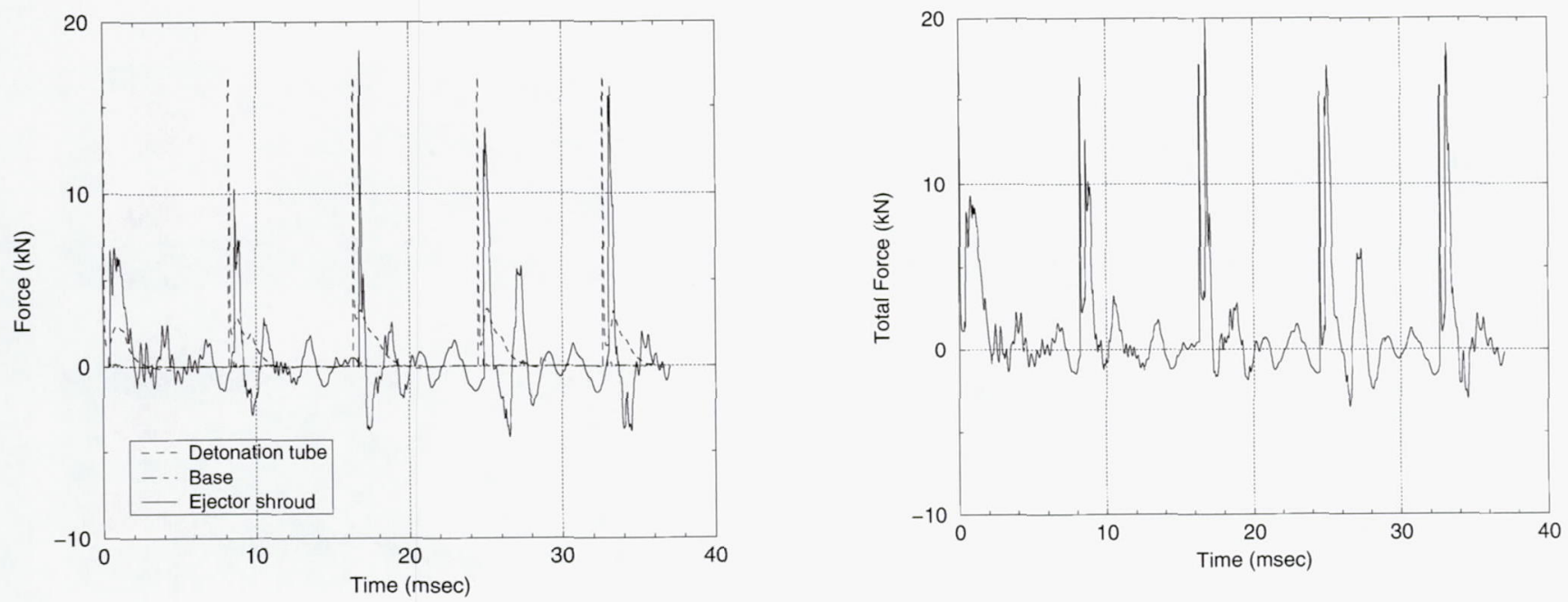

Fig. 11. Force as a function of time for 5 PDE cycles
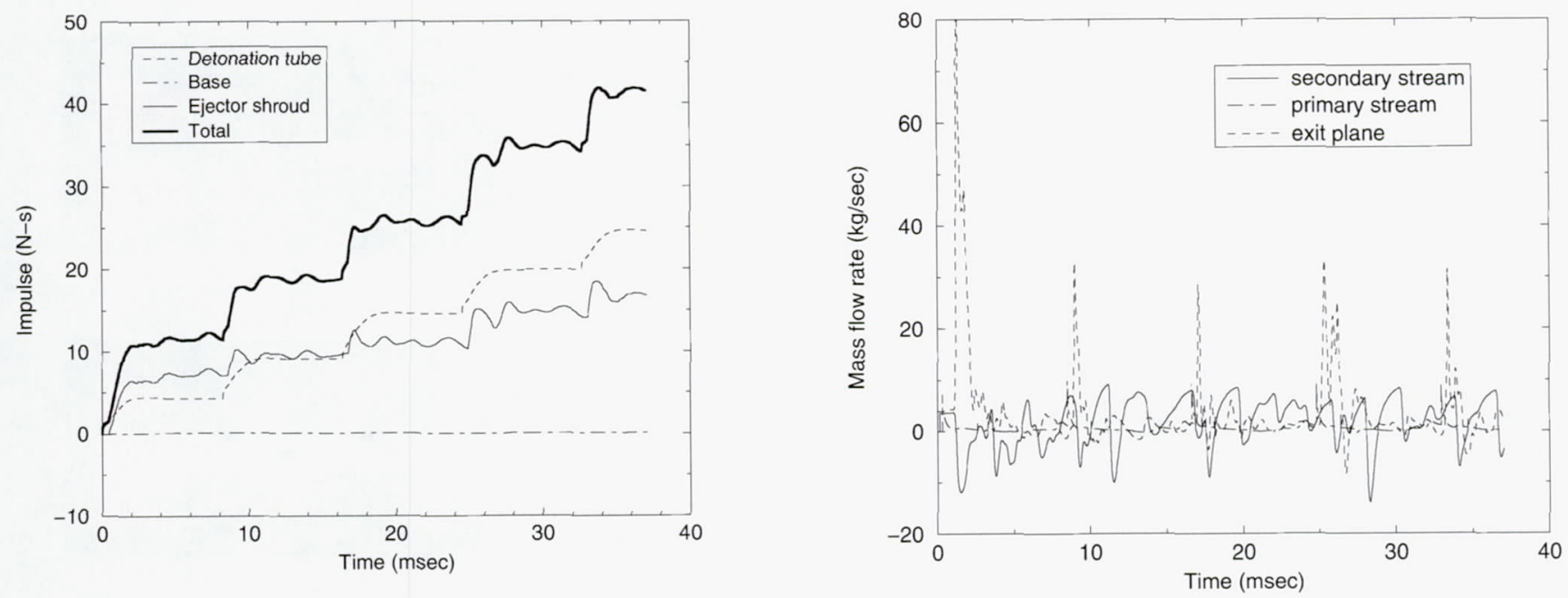

Fig. 12. Impulse and mass flow rate as a function of time for 5 PDE cycles 


\begin{tabular}{|c|c|c|c|}
\hline \multicolumn{3}{|c|}{ REPORT DOCUMENTATION PAGE } & $\begin{array}{l}\text { Form Approved } \\
\text { OMB No. 0704-0188 }\end{array}$ \\
\hline \multicolumn{4}{|c|}{$\begin{array}{l}\text { Public reporting burden for this collection of information is estimated to average } 1 \text { hour per response, including the time for reviewing instructions, searching existing data sources } \\
\text { gathering and maintaining the data needed, and completing and reviewing the collection of information. Send comments regarding this burden estimate or any other aspect of this } \\
\text { collection of information, including suggestions for reducing this burden, to Washington Headquarters Services, Directorate for Information Operations and Reports, } 1215 \text { Jefferson } \\
\text { Davis Highway, Suite 1204, Arlington, VA 22202-4302, and to the Office of Management and Budget, Paperwork Reduction Project (0704-0188), Washington, DC } 20503 \text {. }\end{array}$} \\
\hline 1. AGENCY USE ONLY (Leave blank) & $\begin{array}{l}\text { 2. REPORT DATE } \\
\text { October } 2002\end{array}$ & 3. REPORT TYPE A & $\begin{array}{l}\text { ID DATES COVERED } \\
\text { echnical Memorandum }\end{array}$ \\
\hline \multicolumn{3}{|c|}{$\begin{array}{l}\text { 4. TITLE AND SUBTITLE } \\
\text { Multiple-Cycle Simulation of a Pulse Detonation Engine Ejector }\end{array}$} & 5. FUNDING NUMBERS \\
\hline $\begin{array}{l}\text { 6. AUTHOR(S) } \\
\text { S. Yungster and H.D. Perkins }\end{array}$ & & & $w 0-100-40-15-00$ \\
\hline \multicolumn{3}{|c|}{$\begin{array}{l}\text { 7. PERFORMING ORGANIZATION NAME(S) AND ADDRESS(ES) } \\
\text { National Aeronautics and Space Administration } \\
\text { John H. Glenn Research Center at Lewis Field } \\
\text { Cleveland, Ohio } 44135-3191\end{array}$} & $\begin{array}{l}\text { 8. PERFORMING ORGANIZATION } \\
\text { REPORT NUMBER } \\
\text { E-13570 }\end{array}$ \\
\hline \multicolumn{3}{|c|}{$\begin{array}{l}\text { 9. SPONSORING/MONITORING AGENCY NAME(S) AND ADDRESS(ES) } \\
\text { National Aeronautics and Space Administration } \\
\text { Washington, DC 20546-0001 }\end{array}$} & $\begin{array}{l}\text { 10. SPONSORING/MONITORING } \\
\text { AGENCY REPORT NUMBER } \\
\text { NASA TM-2002-211888 } \\
\text { ICOMP-2002-05 } \\
\text { AIAA-2002-3630 }\end{array}$ \\
\hline \multicolumn{4}{|c|}{$\begin{array}{l}\text { 11. SUPPLEMENTARY NOTES } \\
\text { Prepared for the 38th Joint Propulsion Conference and Exhibit, cosponsored by the AIAA, ASME, SAE, and ASEE, } \\
\text { Indianapolis, Indiana, July 7-10, 2002. S. Yungster, Institute for Computational Mechanics in Propulsion, Brook Park, } \\
\text { Ohio 44142; and H.D. Perkins, NASA Glenn Research Center. Responsible person, Charles Trefney, Turbomachinery } \\
\text { and Propulsion Systems Division, NASA Glenn Research Center, organization code 5880, 216-433-2162. }\end{array}$} \\
\hline \multicolumn{3}{|c|}{$\begin{array}{l}\text { 12a. DISTRIBUTION/AVAILABILITY STATEMENT } \\
\text { Unclassified - Unlimited } \\
\text { Subject Category: } 07 \\
\begin{array}{l}\text { Available electronically at http://gltrs.grc.nasa.gov } \\
\text { This publication is available from the NASA Center for AeroSpace Information, 301-621-0390. }\end{array}\end{array}$} & 12b. DISTRIBUTION CODE \\
\hline
\end{tabular}

13. ABSTRACT (Maximum 200 words)

This paper presents the results of a study involving single and multiple-cycle numerical simulations of various PDEejector configurations utilizing hydrogen-oxygen mixtures. The objective was to investigate the thrust, impulse and mass flow rate characteristics of these devices. The results indicate that ejector systems can utilize the energy stored in the strong shock wave exiting the detonation tube to augment the impulse obtained from the detonation tube alone. Impulse augmentation ratios of up to 1.9 were achieved. The axial location of the converging-diverging ejectors relative to the end of the detonation tube were shownto affect the performance of the system.

\section{SUBJECT TERMS}

Pulsed detonation engine; Unsteady reacting flows; Computational fluid dynamics

\begin{tabular}{|c|c|}
\hline $\begin{array}{c}\text { 17. SECURITY CLASSIFICATION } \\
\text { OF REPORT }\end{array}$ & $\begin{array}{c}\text { 18. SECURITY CLASSIFICATION } \\
\text { OF THIS PAGE } \\
\text { Unclassified }\end{array}$ \\
Unclassified
\end{tabular}

19. SECURITY CLASSIFICATION OF ABSTRACT Unclassified
15. NUMBER OF PAGES

16

16. PRICE CODE

\section{LIMITATION OF ABSTRACT}

Standard Form 298 (Rev. 2-89)

Prescribed by ANSI Std. Z39-18 298-102 